\title{
Effects of Natural Gas Compositions on CNG Fast Filling Process for Buffer Storage System
}

\author{
M. Farzaneh-Gord, H. Reza Rahbari and M. Deymi-Dashtebayaz \\ The Faculty of Mechanical Engineering, Shahrood University of Technology, Shahrood - Iran \\ e-mail: mahmood.farzaneh@yahoo.co.uk - rahbarihamidreza@yahoo.com - meh_deimi@yahoo.com
}

\begin{abstract}
Résumé - Effets des compositions de gaz naturel sur le processus de remplissage rapide de GNC pour un système de stockage tampon - La modélisation précise du processus de remplissage rapide des bouteilles de Gaz Naturel Comprimé (GNC) pour l'alimentation de véhicules constitue un processus complexe et doit être parfaitement étudiée. Les conditions finales dans la bouteille doivent satisfaire à des normes de sécurité. La composition du gaz naturel joue un rôle important sur les propriétés thermodynamiques et en conséquence, sur le processus de remplissage rapide et ces conditions finales. Une analyse théorique a été développée pour étudier les effets de la composition du gaz naturel sur le processus de remplissage d'une bouteille de Gaz Naturel Véhicule (GNV) embarquée. La bouteille est considérée comme un système localisé. L'analyse est basée sur les lois de la thermodynamique et de conservation de masse. Les propriétés requises de mélanges de gaz naturel ont été calculées en s'appuyant sur l'équation d'état (EOS; Equation of State) AGA8 et les relations de la thermodynamique. Les résultats, présentés pour un système adiabatique, montrent que la composition du gaz naturel a des effets importants sur le processus de remplissage et les conditions finales dans la bouteille. En outre, le gaz présentant un moindre pourcentage de méthane dans sa composition est plus approprié pour le processus de remplissage.
\end{abstract}

\footnotetext{
Abstract - Effects of Natural Gas Compositions on CNG Fast Filling Process for Buffer Storage System - The accurate modeling of the fast-fill process occurring in Compressed Natural Gas (CNG) fuelled vehicle storage cylinders is a complex process and should be thoroughly studied. Final in-cylinder conditions should meet appropriate cylinder safety standards. The composition of natural gas plays an important role on its thermodynamic properties and consequently, on the fast-fill process and the final conditions. Here, a theoretical analysis has been developed to study the effects of the natural gas composition on the filling process of an onboard Natural Gas Vehicle (NGV) cylinder. The cylinder is assumed as a lumped system. The analysis is based on laws of thermodynamics and mass balance. Based on AGA8 Equation of State (EOS) and thermodynamics relationships, the required properties of natural gas mixtures have been calculated. The results are presented for an adiabatic system. The results show that the compositions of natural gas have great effects on the filling process and final in-cylinder conditions. Furthermore, the gas with less methane percentage in its composition is more suitable for the filling process.
} 


\section{NOMENCLATURE}

$\begin{array}{ll}A & \text { Area }\left(\mathrm{m}^{2}\right) \\ B & \text { Second virial coefficient } \\ C_{d} & \text { Orifice discharge coefficient } \\ c_{p}, c_{v} & \text { Constant pressure \& volume specific heats }(\mathrm{kJ} / \mathrm{kg} . \mathrm{K}) \\ g & \text { Gravitational acceleration }\left(\mathrm{m} / \mathrm{s}^{2}\right) \\ h & \text { Specific enthalpy }(\mathrm{kJ} / \mathrm{kg}) \\ K_{i j} & \text { Binary interaction parameter } \\ \dot{m} & \text { Mass flow rate }(\mathrm{kg} / \mathrm{s}) \\ M & \text { Molecular weight }(\mathrm{kg} / \mathrm{kmol}) \\ M_{w} & \text { Molecular weight } \\ N & \text { Number of component in gas mixture } \\ n & \text { Number of experimental data } \\ P & \text { Pressure }(\text { bar or Pa) } \\ \dot{Q} & \text { Heat transfer rate }(\mathrm{kW}) \\ T & \text { Temperature }\left(\mathrm{K} \text { or }{ }^{\circ} \mathrm{C}\right) \\ u & \text { Internal energy }(\mathrm{kJ} / \mathrm{kg}) \\ u_{m} & \text { Molar internal energy } \\ h & \text { Enthalpy }(\mathrm{kJ} / \mathrm{kg}) \\ s & \text { Entropy }(\mathrm{kJ} / \mathrm{K}) \\ t & \text { Time }(\mathrm{s}) \\ v & \text { Specific volume }\left(\mathrm{m}^{3} / \mathrm{kg}\right) \\ V & \text { Velocity }(\mathrm{m} / \mathrm{s}) \\ W & \text { Actual work }(\mathrm{kJ} / \mathrm{kg}) \\ \dot{W} & \text { Actual work rate }(\mathrm{kW} \text { or } \mathrm{MW}) \\ z & \text { Height }(\mathrm{m}) \\ Z & \text { Compressibility factor } \\ \rho & \text { Density }\left(\mathrm{kg} / \mathrm{m}^{3}\right) \\ \gamma & \text { Isentropic exponent } \\ & \end{array}$

\section{Subscript}

C NGV onboard cylinder

$R \quad$ Reservoir tank

$i \quad$ Initial or inlet condition

$r \quad$ Recent

$s \quad$ Start of filling process

$a, \infty$ Ambient

av Average

gen Generation

1 Reservoir tank 1

2 Reservoir tank 2

3 Reservoir tank 3

\section{Greek Letters}

$\rho_{m} \quad$ Molar density

$\rho_{r} \quad$ Reduce density $\gamma \quad$ Gas gravity

$\mu_{J} \quad$ Joule-Thomson coefficient

$v_{m}$ Molar specific volume

\section{INTRODUCTION}

Compressed Natural Gas (CNG) is considered as a clean alternative to other car fuels such as gasoline (petrol) and diesel [1]. There are millions of Natural Gas Vehicles (NGV) on the streets and that number is growing continuously. Especially for urban vehicles, natural gas is regarded as an environmentally friendly fuel [2]. To ensures, safe and efficient use of NGVs, it is essential to investigate the effects of various parameters on filling process and final in-cylinder conditions.

The NGVs usually receive natural gas from high pressure reservoirs at the fuelling stations during filling. The onboard vehicle storage cylinders encountered a rise in in-cylinder temperature during the filling. This temperature rise decreases the density of the gas, resulting in an under-filled cylinder, relative to its rated specification. If this temperature rise is not compensated for in the fuelling station, by transiently over-pressurizing the cylinder, the vehicle driver will experience a reduced driving range.

The onboard storage capacity of NGV is a critical issue to the wide spread marketing of these alternate fuelled vehicles. $\mathrm{CNG}$ is dispensed to an NGV through a process known as the fast fill process, since it is completed in less than five minutes. Under-filling of NGV cylinders could occur at the fuelling stations, at ambient temperatures greater than $30^{\circ} \mathrm{C}$. The resulting reduced driving range of the vehicle is a serious obstacle which the gas industry is striving to overcome, without resorting to unnecessarily high fuelling station pressures, or by applying extensive over-pressurization of the cylinder during the fuelling operation. Undercharged storage cylinders are a result of the elevated temperature which occurs in the NGV storage cylinder, due to compression and other processes.

The standards use a settled service pressure of either $20 \mathrm{MPa}$ (2 $900 \mathrm{psi}$ ) or $24.5 \mathrm{MPa}$ (3600 psi) for an onboard NGV cylinder. They allow for overfilling to take account of the increased temperature generated during fast filling and therefore, use the overfilled condition as the upper limit in the pressure cycle tests. A maximum pressure of $26 \mathrm{MPa}$ is permitted in ISO 11439 regardless of ambient temperature. The cylinders are generally designed to be filled to service pressure 1000 times per year of service life, up to a maximum of 20 years [3]. They are expected to operate effectively in temperatures from $-40^{\circ} \mathrm{C}$ to $65^{\circ} \mathrm{C}$ with occasional temperature rises up to $82^{\circ} \mathrm{C}$.

The NGV industry has made excellent advancements in the industry to provide a system to refuel a NGV in a comparable to that of a gasoline dispenser. The problem with 
the long refuelling time has been remedied, for the most part, to be comparable to the fill time $(<5 \mathrm{~min})$ taken to fill a gasoline powered automobile. This fill time can be referred to as a fast fill or rapid charge.

There have been limited researches in the field of filling process modeling in literature. Kountz [4] were progenitor in this field that modeled fast filling process of an NGV cylinder based on first law of thermodynamics. They expanded a computer program to simulate fast filling process for a single reservoir based on real gas. Kountz et al. [5-8], have also developed a natural gas dispenser control algorithm that insures complete filling of NGV cylinders under a fast fill scenario. The researchers are also under way to model fast filling of hydrogen-based fuelling infrastructure, including work of Liss and Richards [9], Liss et al. [10] and Newhouse and Liss [11] have studied fast filling of the hydrogen cylinder using the number of experiments. They reported a high temperature increase in the cylinder during the process.

A few experimental studies were also carried out to study fast filling of the natural gas cylinder, including work of Thomas et al. [12] and Shiply [13]. Shiply [13] concluded that ambient temperature change can have an effect on the fast fill process. He also concluded that, the test cylinder was under-filled every time it was rapidly recharged.

Farzaneh-Gord et al. [14] and Farzaneh-Gord [15] have also modeled fast filling process. They developed a computer programme based on the Peng-Robinson state equation and methane properties table for single reservoir. They investigated effects of ambient temperature and initial cylinder pressure on final cylinder conditions. In another study, Farzaneh-Gord et al. [16] presented thermodynamics analysis of cascade reservoirs filling process of NGV cylinders. The results of this research indicated that ambient temperature has the big effect on filling process and final NGV cylinder conditions.

Farzaneh-Gord et al. [17] have employed a theoretical analysis to study effects of buffer and cascade storage systems on performance of a CNG fuelling station. It is found that the time (filling time) required for bringing up the NGV onboard cylinder to its final pressure in the buffer storage system is about $66 \%$ less than the cascade storage system. The charged mass for cascade system is about $80 \%$ of the buffer system which gives an advantage to buffer system over cascade one. The biggest advantage of the cascade system over the buffer system is $50 \%$ less entropy generation for this configuration, which probably causes much lower required compressor input work for this configuration comparing to buffer system.

In all previous studies, the natural gas assumed as pure methane or a gas with fixed composition. So the influences of natural gas compositions on filling process and final incylinder values have not been studied. The main purpose of the current study is to investigate the effects of natural gas compositions on filling process and final in-cylinder conditions for a buffer storage system.
Natural gas composition plays a big role on CNG fuel. In a research, Kim et al. [18] have studied the effect of natural gas composition on the performance of a CNG engine. For studying the CNG filling process, it is vital to know thermodynamic properties of natural gas. To compute the thermodynamic properties, the AGA8 Equation of State (EOS) [19, 20] has been employed. The AGA8 EOS has been developed by the American Gas Association (AGA), especially for calculating compressibility factor and density of natural gas for custody transfer. It shows good performance and high accuracy in the temperature range between $143.15 \mathrm{~K}$ and $676.15 \mathrm{~K}$ and for a pressure up to $280 \mathrm{MPa}$. The AGA8 has been also subject to various researches in order to calculate thermodynamics properties of natural gas. Isentropic exponent, Joule-Thomson coefficient and heat capacities at constant pressure and volume are calculated by Maríc et al. [21] and Maríc [22,23]. Farzaneh-Gord et al. [24] has employed AGA8 EOS to calculate the thermal properties of natural gas mixture such as enthalpy and internal energy in addition of the compressibility factor.

In this study, the second law has been employed to calculate the value of the entropy generation theoretically. Entropy generation is corresponded with thermodynamic irreversibilities, which is common in all types of thermal systems. Various sources are accountable for the entropy generation. There have been numerous researches in the field of entropy generation. Bejan [25, 26] have concentrated upon the different mechanisms responsible for entropy generation in applied thermal engineering. Generation of entropy reduces the available work of a system. Therefore, it makes good engineering sense to focus on irreversibilities (see Bejan [25-27]) of heat transfer and fluid flow processes and try to understand the function of related entropy generation mechanisms. Since then, a lot of studies have been carried out to compute the entropy generation and irreversibility profiles for different geometric configurations, flow situations and thermal boundary conditions. Here, entropy generation minimization has been employed as a tool to determine the amount of work destruction during filling process.

In this study, the main objective is to investigate the effects of natural gas composition on filling process of an NGV onboard cylinder. The cylinder is assumed to be filled by connecting to a single high pressure reservoir (commonly called buffer system). The thermodynamic analysis has been employed as a theoretical tool. The theoretical model is developed based on the mass and energy balance and the second law of thermodynamic. Thermodynamic properties and entropy generation in the cylinder are calculated during the filling process. The thermodynamic properties of natural gas mixture are computed based on AGA8 EOS and thermodynamics relationships. 


\section{NATURAL GAS COMPOSITIONS}

Natural gas is a mixture of several components with various properties. Therefore, its thermodynamics properties are dependant on its components. To obtain the properties accurately, the effect of the gas compositions must be also considered. For this purpose, the AGA8 EOS has been employed. Table 1 shows the molar percent of four typical compositions employed in this study. These gases are extracted from the various regions within Iran [28]. These gases have been selected due to highest different in their compositions among Iranian pipeline natural gases.

TABLE 1

Mole fraction of natural gas extracted from various region of Iran [28]

\begin{tabular}{c|c|c|c|c}
\hline \multirow{2}{*}{ Component } & \multicolumn{4}{|c}{ Mole fraction (\%) } \\
\cline { 2 - 5 } & Khangiran & Kangan & Turkman gas & Pars \\
\hline $\mathrm{CH}_{4}$ & 98.6 & 90.04 & 94.21 & 87 \\
\hline $\mathrm{C}_{2} \mathrm{H}_{6}$ & 0.59 & 3.69 & 2.25 & 5.4 \\
\hline $\mathrm{C}_{3} \mathrm{H}_{8}$ & 0.09 & 0.93 & 0.53 & 1.7 \\
\hline iso- $\mathrm{C}_{4} \mathrm{H}_{10}$ & 0.02 & 0.2 & 0.36 & 0.3 \\
\hline$n-\mathrm{C}_{4} \mathrm{H}_{10}$ & 0.04 & 0.29 & 0 & 0.45 \\
\hline iso- $\mathrm{C}_{5} \mathrm{H}_{12}$ & 0.02 & 0.14 & 0.26 & 0.13 \\
\hline$n-\mathrm{C}_{5} \mathrm{H}_{12}$ & 0.02 & 0.08 & 0 & 0.11 \\
\hline$n-\mathrm{C}_{6} \mathrm{H}_{14}$ & 0.07 & 0.14 & 0.17 & 0.07 \\
\hline $\mathrm{C}_{7}^{+}$ & 0 & 0.01 & 0.18 & 0.03 \\
\hline $\mathrm{N}_{2}$ & 0.56 & 4.48 & 1.9 & 3.1 \\
\hline $\mathrm{CO}_{2}$ & 0 & 0 & 0.14 & 1.85 \\
\hline
\end{tabular}

\section{CNG FILLING STATION}

Figure 1 shows a typical CNG filling station. Natural gas from the distribution pipeline, usually "low" pressure at $<0.4 \mathrm{MPa}$ or possibly "medium" pressure (1.6 MPa), is compressed using a large multi-stage compressor into a storage system. This system is maintained at a pressure higher than that in the vehicle's onboard storage so that gas flows to the vehicle under differential pressures. Typically, the storage system will operate in the range of $20.5 \mathrm{MPa}$ to $25 \mathrm{MPa}$, while the vehicle's maximum onboard cylinder pressure is $20 \mathrm{MPa}$. In order to make the utilization of the compressor and storage system more efficient, fast fill CNG stations usually operate using a three-stage "cascade" storage system. In this storage system, reservoir cylinders are put into an order of ascending pressure. Figure 1 shows a schematic diagram of a cascade storage system. During fast filling, the onboard cylinder is first connected to the low-pressure reservoir. As the flow rate reaches a pre-set level the system is first switched to the medium pressure reservoir and then to the high-pressure reservoir to complete the fill. However, in

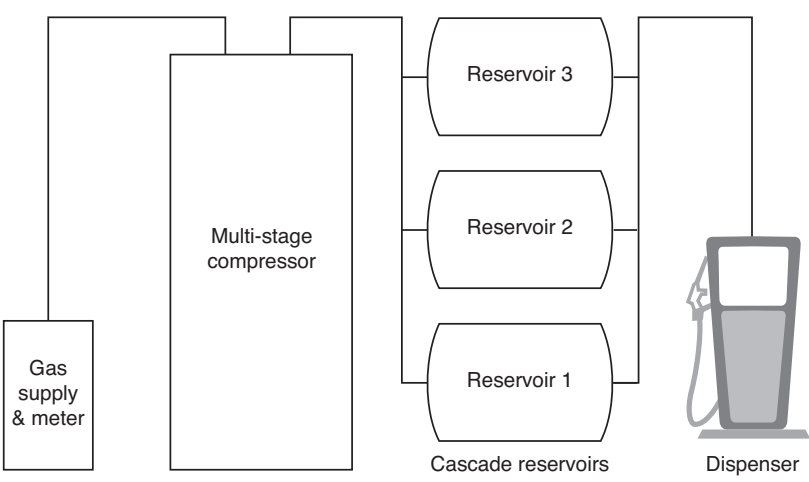

Figure 1

A schematic diagram of NGV filling station.

refilling the station reservoirs the compressor is automatically switched on to fill the high pressure reservoir first and then switches to the medium and the low pressure reservoirs. This ensures that the high pressure reservoir is maintained at maximum pressure all the time, ensuring that vehicles are always supplied with the maximum amount of gas available. Here for sake of simplicity, the pressure assumed to be unchanged during filling processes.

\section{THERMODYNAMIC ANALYSIS}

\subsection{First Law Analysis}

To model the fast filling process and develop a mathematical method, the NGV onboard cylinder is considered as a thermodynamics open system which goes through a quasisteady process.

To develop a theoretical analysis, the continuity and first law of thermodynamics have been applied to the cylinder, to find 2 thermodynamics properties. Considering the onboard NGV cylinder as a control volume and knowing it has only 1 inlet, the continuity (conservation of mass) equation may be written as follows:

$$
\frac{d m_{C}}{d t}=\dot{m}_{i}
$$

In Equation (1), $\dot{m}_{i}$ is the inlet mass flow rate and can be calculated by considering expansion through an orifice. Applying gas dynamics laws [4]:

$$
\begin{aligned}
\dot{m}_{i}=C_{d} \rho_{R} A_{\text {orifice }}\left(\frac{P_{C}}{P_{R}}\right)^{\frac{1}{\gamma}} & \left\{\left(\frac{2 \gamma}{\gamma-1}\right)\left(\frac{P_{R}}{\rho_{R}}\right)\left[1-\left(\frac{P_{C}}{P_{R}}\right)^{\frac{\gamma-1}{\gamma}}\right]\right\}^{\frac{1}{2}} \text { if: } \\
\frac{P_{C}}{P_{R}} & \leq\left(\frac{2}{\gamma+1}\right)^{\frac{\gamma}{\gamma-1}}
\end{aligned}
$$


$\dot{m}_{i}=C_{d} \sqrt{\gamma P_{R} \rho_{R}} A_{\text {orifice }}\left(\frac{2}{\gamma+1}\right)^{\frac{\gamma+1}{2(\gamma-1)}}$ if: $\frac{P_{C}}{P_{R}}>\left(\frac{2}{\gamma+1}\right)^{\frac{\gamma}{\gamma-1}}$

Equation (2) is valid for subsonic flow while Equation (3) is for sonic condition. Discharge coefficient $\left(C_{d}\right)$ is then introduced to consider irreversibility of the flow through an orifice.

The first laws of thermodynamics for a control volume in general form can be written as follow:

$$
\begin{aligned}
& \dot{Q}_{c v}+\sum \dot{m}_{i}\left(h_{i}+V_{i}^{2} / 2+g z_{i}\right)=\sum \dot{m}_{e}\left(h_{e}+V_{e}^{2} / 2+g z_{e}\right) \\
& +d / d t\left[m\left(u+V^{2} / 2+g z\right)\right]_{c v}+\dot{W}_{c v}
\end{aligned}
$$

The work term is zero in the filling process and the change in potential and kinetic energy in NGV cylinder $\left.\left(V^{2} / 2\right)_{c v}\right)$ can be neglected. The equation then could be simplified as below:

$$
\frac{d U_{C}}{d t}=\dot{Q}+\dot{m}_{i}\left(\frac{V_{i}^{2}}{2}+h_{i}\right)
$$

Applying energy balance for the reservoir tank, one could obtain $h_{R}=\frac{V_{i}^{2}}{2}+h_{i}$. Here, the reservoir conditions are assumed to be unchanged, consequently $h_{R}$ is constant throughout the filling process.

Replacing $\frac{V_{i}^{2}}{2}+h_{i}$ with $h_{R}$, Equation (5) further could be simplified as:

$$
\frac{d U_{C}}{d t}=\dot{Q}+\dot{m}_{i} h_{R}
$$

The heat lost from the onboard NGV cylinder to environment could be calculated as:

$$
\dot{Q}=-U_{H C} A_{C}\left(T_{C}-T_{\infty}\right)
$$

That $U_{H C}$ is overall heat transfer coefficient of the cylinder. It controls the rate of heat transfer from the gas within cylinder to the ambient. Higher $U_{H C}$ means lower final incylinder condition. Combining Equations $(1,6)$ and (7), one could obtain an equation as:

$$
\frac{d\left(m_{C} u_{C}\right)}{d t}=-U_{H C} A_{C}\left(T_{C}-T_{\infty}\right)+\frac{d m_{C}}{d t} h_{R}
$$

Or in the following form:

$$
\frac{d\left(m_{C} u_{C}\right)}{d t}-\frac{d\left(m_{C} h_{R}\right)}{d t}=-U_{H C} A_{C}\left(T_{C}-T_{\infty}\right)
$$
form:

The above equation could be rearranged in the following

$$
d\left(m_{C} u_{C}-m_{C} h_{R}\right)=-U_{H C} A_{C}\left(T_{C}-T_{\infty}\right) d t
$$

The above equation could be integrated from "start" of filling, up to "recent" time as:

$$
\int_{s}^{r} d\left(m_{C} u_{C}-m_{C} h_{R}\right)=-\int_{o}^{t} U_{H C} A_{C}\left(T_{C}-T_{\infty}\right) d t
$$

The integration of the above equation for a single reservoir fuelling station resulted to:

$$
m_{C}\left(u_{C}-h_{R}\right)-m_{C s}\left(u_{C s}-h_{R}\right)=-U_{H C} A_{C} \Delta T_{a v} t
$$

When $m_{C}, m_{C s}$ are mass of charged gas at "recent" and "start" of filling process respectively, $\Delta T_{a v}$ is average temperature difference between cylinder and environment which defined as:

$$
\Delta T_{a v}=\frac{1}{t} \int_{o}^{t}\left(T_{C}-T_{\infty}\right) d t
$$

The first law of thermodynamic for the onboard NGV cylinder finally could be written as:

$$
u_{C}=h_{R}-\frac{U_{H C} A_{C} \Delta T_{a v} t}{m_{C}}+\frac{m_{C s}}{m_{C}}\left(u_{C s}-h_{R}\right)
$$

Equations $(2,3)$ and (14) could be employed to calculate the two thermodynamic properties of in-cylinder natural gas at any time.

For an adiabatic system, Equation (14) could be more simplified as:

$$
u_{C}=h_{R}+\frac{m_{C s}}{m_{C}}\left(u_{C s}-h_{R}\right)
$$

And if $m_{C s}=0$, the following relation is valid at any time:

$$
u_{C}=h_{R}
$$

\subsection{The Second Law Analysis}

The second law of thermodynamic adopted in this study, makes it possible to evaluate the entropy generation rate, $\dot{S}_{g e n}$, for flow processes occurring in the storage system of the CNG filling station.

The second law of thermodynamics for an onboard NGV cylinder during filling could be presented as:

$$
\dot{S}_{\text {gen }}=d S_{C} / d t-\dot{Q} / T_{\infty}-\dot{m}_{i} s_{i} \geq 0
$$

Here, all irreversibility assumed to be occurred from inlet to in-cylinder position. This makes an isentropic expansion from reservoir to inlet position, which means $s_{i}=s_{R}$. Considering this assumption and combining Equations $(1,7)$ and $(17)$, the following equation could be obtained:

$$
\dot{S}_{g e n}=\frac{d\left(m_{C} s_{C}\right)}{d t}-\frac{d m_{C}}{d t} s_{R}+U_{H C} A_{C}\left(T_{C}-T_{\infty}\right) / T_{\infty}
$$

Or in the following form:

$$
\dot{S}_{g e n} d t=d\left(m_{C} s_{C}-m_{C} s_{R}\right)+U_{H C} A_{C}\left(T_{C}-T_{\infty}\right) / T_{\infty} d t
$$


The above equation could be integrated from "start" of filling to "recent" time as below:

$$
S_{g e n}=\int_{s}^{r} d\left(m_{C} s_{C}-m_{C} s_{R}\right)+\int_{s}^{r} \frac{U_{H C} A_{C}\left(T_{C}-T_{\infty}\right)}{T_{\infty}} d t
$$

For a fuelling station with a single reservoir in which $s_{R}$ remains constant throughout the filling process, the integration of the above equation resulted to a simple equation as:

$$
S_{g e n}=m_{C}\left(s_{C}-s_{R}\right)-m_{C s}\left(s_{C s}-s_{R}\right)+\frac{U_{H C} A_{C} \Delta T_{a v} t}{T_{\infty}}
$$

Equation (21) could be more simplified for an adiabatic system as:

$$
S_{g e n}=m_{C}\left(s_{C}-s_{R}\right)-m_{C s}\left(s_{C s}-s_{R}\right)
$$

And if the cylinder is empty at start of filling process $\left(m_{C s}=0\right)$ the following relation could be obtained:

$$
S_{g e n, \max }=m_{C}\left(s_{C}-s_{R}\right)
$$

\section{COMPUTING NATURAL GAS THERMODYNAMICS PROPERTIES}

As discussed, a few thermodynamic properties of natural gas have to be calculated in order to analyze the filling process. These properties are density (or specific volume), internal energy and entropy. The method for calculating these properties are discussed in this section. The detailed methods for calculating most of natural gas thermodynamic properties are presented in Farzaneh-Gord and Rahbari [29-30]. The thermodynamics relationship presented here, could be also found in most of thermodynamic text books including Moran and Shapiro [31].

\subsection{AGA8 EOS}

The general form of AGA8 EOS is presented as follows [19]:

$$
P=Z \rho_{m} R T
$$

In Equation (24), $P$ is pressure, $Z$ is compressibility factor, $\rho_{m}$ is molar density, $R$ is universal gas constant and $T$ is temperature.

To calculate compressibility factor, the following equation is presented [19]:

$$
Z=1+B \rho_{m}-\rho_{r} \sum_{n=13}^{18} C_{n}^{*}+\sum_{n=13}^{18} C_{n}^{*} D_{n}^{*}
$$

In Equation (25), $\rho_{r}$ is reduced density and defined as follows:

$$
\rho_{r}=K^{3} \rho_{m}
$$

where in Equation (26), $K$ is mixture size parameter and calculated using following equation [19]:

$$
K^{5}=\left(\sum_{i=1}^{N} x_{i} K_{i}^{\frac{5}{2}}\right)^{2}+2 \sum_{i=1}^{N-1} \sum_{j=i+1}^{N} x_{i} x_{j}\left(K_{i j}{ }^{5}-1\right)\left(K_{i} K_{j}\right)^{\frac{5}{2}}
$$

In Equation (27), $x_{i}$ is mole fraction of component $i$ in the mixture, $x_{j}$ is mole fraction of component $j$ in mixture, $K_{i}$ is size parameter of component $i, K_{j}$ is size parameter of component $j, K_{i j}$ is binary interaction parameter for size and $N$ is number of component in gas mixture. The values for these parameters could be found in [19].

In Equation (25), $B$ is second virial coefficient and given by the following equation [19]:

$$
B=\sum_{n=1}^{18} a_{n} T^{-u_{n}} \sum_{i=1}^{N} \sum_{j=1}^{N} x_{i} x_{j} B_{n i j}{ }^{*} E_{i j}{ }^{u_{n}}\left(K_{i} K_{j}\right)^{\frac{3}{2}}
$$

In Equation (28), $B_{n i j}{ }^{*}$ and $E_{i j}$ are defined by the following equations [19]:

$$
\begin{gathered}
B_{n i j}{ }^{*}=\left(G_{i j}+1-g_{n}\right)^{g_{n}}\left(Q_{i} Q_{j}+1-q_{n}\right)^{q_{n}} \times \\
\left(F_{i}^{1 / 2} F_{j}^{1 / 2}+1-f_{n}\right)^{f_{n}}\left(S_{i} S_{j}+1-s_{n}\right)^{s_{n}}\left(W_{i} W_{j}+1-w_{n}\right)^{w_{n}} \\
E_{i j}=E_{i j}{ }^{*}\left(E_{i} E_{j}\right)^{1 / 2}
\end{gathered}
$$
[19]:

In Equation (29), $G_{i j}$ is defined by the following equation

$$
G_{i j}=\frac{G_{i j} *\left(G_{i}+G_{j}\right)}{2}
$$

In Equations (27) to (31), $N$ is the number of component in gas mixture, $a_{n}, f_{n}, g_{n}, q_{n}, s_{n}, u_{n}, w_{n}$ are the Equation of State parameters, $E_{i}, F_{i}, G_{i}, K_{i}, Q_{i}, S_{i}, W_{i}$ are the corresponding characterization parameters and $E_{i j}{ }^{*}, G_{i j}{ }^{*}$ are corresponding binary interaction parameters.

In Equation (25), $C_{n}{ }^{*} ; n=1, \ldots, 58$ are temperature dependent coefficients and defined by the following equation [19]:

$C_{n}^{*}=a_{n}\left(G+1-g_{n}\right)^{g_{n}}\left(Q^{2}+1-q_{n}\right)^{q_{n}}\left(F+1-f_{n}\right)^{f_{n}} U_{n}^{u_{n}} T^{-u_{n}}$

In Equation (32), $G, F, Q, U$ are the mixture parameters and defined by the following equations [19]:

$$
\begin{aligned}
U^{5} & =\left(\sum_{i=1}^{N} x_{i} E_{i}^{\frac{5}{2}}\right)^{2}+2 \sum_{i=1}^{N-1} \sum_{j=i+1}^{N} x_{i} x_{j}\left(U_{i j}{ }^{5}-1\right)\left(E_{i} E_{j}\right)^{\frac{5}{2}} \\
G & =\sum_{i=1}^{N} x_{i} G_{i}+2 \sum_{i=1}^{N-1} \sum_{j=i+1}^{N} x_{i} x_{j}\left(G_{i j}{ }^{*}-1\right)\left(G_{i}+G_{j}\right)
\end{aligned}
$$




$$
\begin{aligned}
& Q=\sum_{i=1}^{N} x_{i} Q_{i} \\
& F=\sum_{i=1}^{N} x_{i}^{2} F_{i}
\end{aligned}
$$

where in Equation (33), $U_{i j}$ is the binary interaction parameter for mixture energy.

In Equation (25), $D_{n}^{*}$ is defined by the following equation:

$$
D_{n}^{*}=\left(b_{n}-c_{n} k_{n} \rho_{r}^{k_{n}}\right) \rho_{r}^{b_{n}} \exp \left(-c_{n} \rho_{r}^{k_{n}}\right)
$$

Coefficients of Equation (37) are introduced in Reference [19].

Substituting Equation (25) to (37) in Equation (24), and by knowing the temperature, pressure and composition, the only unknown parameter is molar density. The modified Equation (24) is then solved using Newton-Raphson iterative method to calculate the molar density [19].

The density of natural gas is then calculated by the following equation:

$$
\rho=M_{w} \rho_{m}
$$

where, $M_{w}$ is molecular weight of the mixture.

AGA8 EOS is developed for specific range of the natural gas components. Table 2 shows range of the components to which AGA8 EOS could be employed [19]. The range of AGA8 suitability, made it well suited for CNG filling

\begin{tabular}{|c|c|c|}
\hline Component (mole\%) & Normal range & Expanded range \\
\hline Methane & 45 to 100 & 0 to 100 \\
\hline Nitrogen & 0 to 50 & 0 to 100 \\
\hline Carbon dioxide & 0 to 30 & 0 to 100 \\
\hline Ethane & 0 to 10 & 0 to 100 \\
\hline Propane & 0 to 4 & 0 to 12 \\
\hline Total butanes & 0 to 1 & 0 to 6 \\
\hline Total pentanes & 0 to 0.3 & 0 to 4 \\
\hline Hexanes plus & 0 to 0.2 & 0 to Dew point \\
\hline Helium & 0 to 0.2 & 0 to 3 \\
\hline Hydrogen & 0 to 10 & 0 to 100 \\
\hline Carbon monoxide & 0 to 3 & 0 to 3 \\
\hline Argon & 0 & 0 to 1 \\
\hline Oxygen & 0 & 0 to 21 \\
\hline Water & 0 to 0.05 & 0 to Dew point \\
\hline Hydrogen sulfide & 0 to 0.02 & 0 to 100 \\
\hline
\end{tabular}
process.

TABLE 2

Range of gas mixture characteristics in AGA8 model [19]

\subsection{Internal Energy Calculation (u)}

Assuming internal energy as a function of temperature and molar specific volume, the internal energy residual function is defined as follows [31]:

$$
u_{m}-u_{m, I}=\int_{v_{m}, I}^{v_{m}}\left[T\left(\frac{\partial P}{\partial T}\right)_{v_{m}}-P\right] d v_{m}
$$

In Equation (39), $u_{m}$ is the molar internal energy for real gas and $u_{m, I}$ is the molar internal energy for ideal gas. Using Equation (24), partial differential relation in Equation (39) could be calculated by below equation [31]:

$$
\left(\frac{\partial P}{\partial T}\right)_{v_{m}}=\left(\frac{\partial P}{\partial T}\right)_{\rho_{m}}=R \rho_{m}\left[Z+T\left(\frac{\partial Z}{\partial T}\right)_{\rho_{m}}\right]
$$

Substitute Equation (40) in Equation (39) and changing variables of $v_{m}$ to $\rho_{m}$, the following equation for calculating internal energy could be obtained [31]:

$$
u_{m}-u_{m, I}=-R T^{2} \int_{0}^{\rho_{m}}\left(\frac{\partial Z}{\partial T}\right)_{\rho_{m}} \frac{d \rho_{m}}{\rho_{m}}
$$

Molar internal energy for ideal gas could be calculated using the following equation:

$$
u_{m, I}=h_{m, I}-P v_{m}=h_{m, I}-R T
$$

In Equation (42), $h_{m, I}$ is the molar enthalpy for ideal gas and calculated using below equation:

$$
h_{m, I}=\sum_{j=1}^{N} x_{j} h_{m, i}{ }^{j}
$$

where in Equation (43), $h_{m, i}{ }_{i}^{j}$ is the molar enthalpy for ideal gas and for component $j$ in the mixture. It could be represented as [31]:

$$
h_{m, i}{ }^{j}=h_{m, i 0}{ }^{j}+a_{j} T+b_{j} c_{j} \operatorname{coth}\left(\frac{c_{j}}{T}\right)-d_{j} e_{j} \tanh \left(\frac{e_{j}}{T}\right)
$$

Coefficients in Equation (44) are given in Reference [31]. $h_{m, i 0}{ }^{j}$ is the molar enthalpy for ideal gas of component $j$ in the mixture at reference state $\left(25^{\circ} \mathrm{C}, 101.325 \mathrm{kPa}\right)$.

Also, the internal energy per unit mass is defined as follows:

$$
u=\frac{u_{m}}{M_{w}}
$$

\subsection{Joule-Thomson Coefficient Calculation $(\mu)$}

Joule-Thomson coefficient is defined as follows [31]:

$$
\mu_{J}=\left(\frac{\partial T}{\partial P}\right)_{h}
$$


where $\mu_{J}$, is Joule-Thomson coefficient and $h$ is enthalpy. Total differential for enthalpy related to temperature and molar volume is [31]:

$$
d h_{m}=C_{m, P} d T+\left[v_{m}-T\left(\frac{\partial v_{m}}{\partial T}\right)_{P}\right] d P
$$

Considering the definition of Joule-Thomson coefficient, $\left(\frac{\partial T}{\partial P}\right)_{h}$, one could obtain the following relation for calculating Joule-Thomson coefficient [31]:

$$
\mu_{J}=\left(\frac{\partial T}{\partial P}\right)_{h}=\frac{\left[T\left(\frac{\partial v_{m}}{\partial T}\right)_{P}-v_{m}\right]}{C_{m, P}}
$$

Maríc [23] calculated Joule-Thomson coefficient for natural gas mixtures using AGA8 EOS and obtained similar results.

\subsection{Entropy Calculation $(s)$}

Using one of Maxwell's relations, the following relationship for entropy could be derived [31]:

$$
\left(\frac{\partial s_{m}}{\partial v_{m}}\right)_{T}=\left(\frac{\partial P}{\partial T}\right)_{v_{m}}
$$

In Equation (49), $s_{m}$ is the molar entropy. By integrating Equation (49) to the specific molar volume and changing variables, the following equation for molar entropy could be obtained [31]:

$$
s_{m}=s_{m, I}-R \int_{0}^{\rho_{m}}\left[Z+T\left(\frac{\partial Z}{\partial T}\right)_{\rho_{m}}\right] \frac{d \rho_{m}}{\rho_{m}}
$$

In Equation (50), $s_{m}$ is the molar entropy for real gas and $s_{m, I}$ is the molar entropy for ideal gas. Molar entropy for ideal gas defines as follow:

$$
s_{m, I}=\sum_{j=1}^{N} x_{j} s_{m, i}{ }^{j}
$$

In Equation (51), $s_{m, i}{ }^{j}$ is the molar entropy for ideal gas of component $j$ in the mixture which could be presented as below:

$$
s_{m, i}{ }^{j}\left(T, P, x_{j}\right)=s_{m, i}{ }^{j}(T)-R \operatorname{Ln}\left(x_{j} P\right)
$$

In Equation (52), $s_{m, i}^{j}(T)$ is the molar entropy for ideal gas of component $j$ that is a function of the temperature and is defined by the following equation [31]:

$$
\begin{aligned}
& s_{m, i}{ }^{j}(T)=s_{m, i 0}{ }^{j}+a_{j} \operatorname{Ln}(T) \\
& +b_{j}\left[\left(\frac{c_{j}}{T}\right) \operatorname{coth}\left(\frac{c_{j}}{T}\right)-\operatorname{Ln}\left(\sinh \left(\frac{c_{j}}{T}\right)\right)\right] \\
& -d_{j}\left[\left(\frac{e_{j}}{T}\right) \operatorname{coth}\left(\frac{e_{j}}{T}\right)-\operatorname{Ln}\left(\cosh \left(\frac{e_{j}}{T}\right)\right)\right]
\end{aligned}
$$

In Equation (53), $s_{m, i 0}{ }^{j}$ is the molar entropy at reference temperature. Coefficients for Equation (53) are given in Reference [32]. Entropy per unit mass then could be calculated as follows:

$$
s=\frac{s_{m}}{M_{w}}
$$

\section{THE NUMERICAL PROCEDURE}

The procedure for computing the natural gas in-cylinder properties begins by knowing the initial conditions (pressure and temperature). The other initial thermodynamic properties (including $h_{R}=u_{R}+(p v)_{R}$ ) are calculated by employing AGA8 EOS discussed in Section 4. Equation (2) (or 3) is employed to calculate the inlet mass flow rate. Equation (1) is then employed to compute the in-cylinder mass and consequently specific volume within the cylinder using first order Euler numerical scheme. Similarly, Equation (15) is solved to calculate the in-cylinder specific internal energy of hydrogen at the new time step. Upon determination of specific internal energy and specific volume, other properties are found from the AGA8 EOS by the trial and error method.

\section{RESULTS AND DISCUSSION}

In this study, the NGV onboard cylinder is considered as a lump adiabatic system as a result, the orifice size and inlet mass flow rate, have no effect on the final in-cylinder temperature and pressure. The orifice diameter and the cylinder volume were considered to be $1 \mathrm{~mm}$ and 67 liters respectively. The discharge coefficient is also assumed to be one. The results have been presented here for a single reservoir storage as shown in Figure 2.

The Joule-Thomson coefficient $\left(\mu_{J}\right)$ plays an important role during filling process. A gas with positive $\mu_{J}$, cools upon expansion. The rate of change of temperature with respect to pressure directly related to the coefficient value. It is instructive to examine the coefficient during the filling process. Figure 3 shows the effects of natural gas compositions on the in-cylinder $\mu_{J}$ coefficient during the filling process with initial conditions of $300 \mathrm{~K}$ and $0.101325 \mathrm{MPa}$. It could be noticed

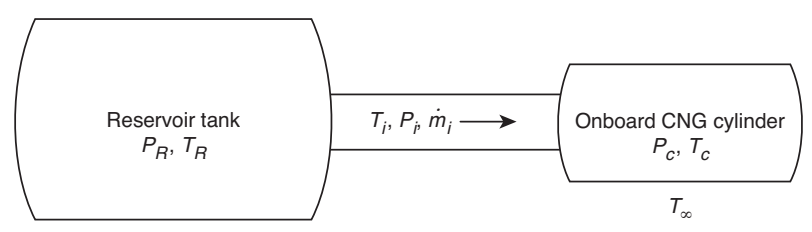

Figure 2

A schematic diagram of thermodynamic system. 
that, there is a jump in $\mu_{J}$ profiles during early part of filling. The $\mu_{J}$ coefficient is positive throughout of the filling so the temperature should drop as pressure reduces. Comparing the $\mu_{J}$ values for various gases, the $\mu_{J}$ is higher for the gas with lower methane percentage in the composition (for current study, the Pars natural gas).

Figure 4 shows the effects of natural gas compositions on dynamic in-cylinder temperature during filling with initial conditions of $300 \mathrm{~K}$ and $0.101325 \mathrm{MPa}$. Note, from Figure 4, that the in-cylinder temperature dips during the early stages of charging before rising to a final value. The reason for the

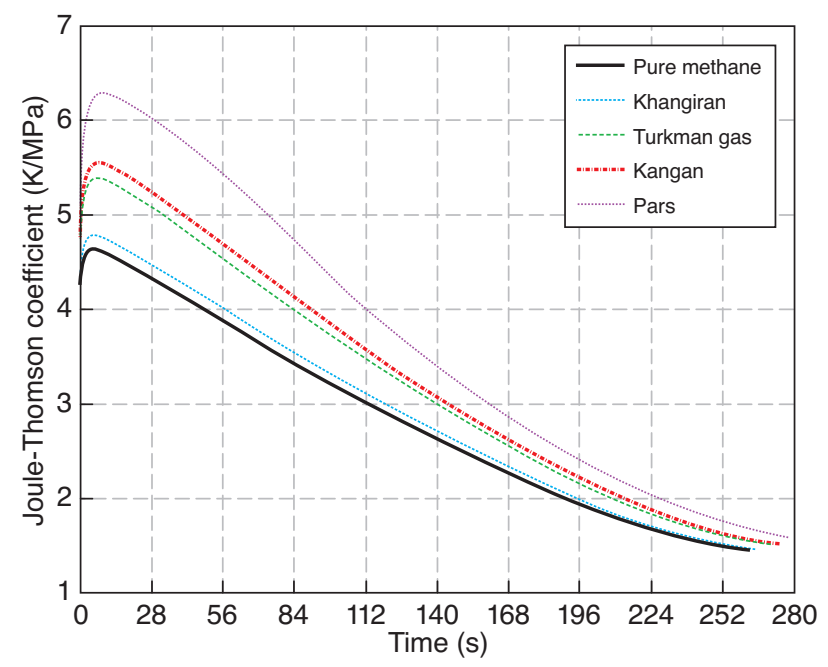

Figure 3

In-cylinder Joule-Thomson coefficient of studied natural gas during the filling while initial conditions kept constant at $300 \mathrm{~K}$ and $0.101325 \mathrm{MPa}$.

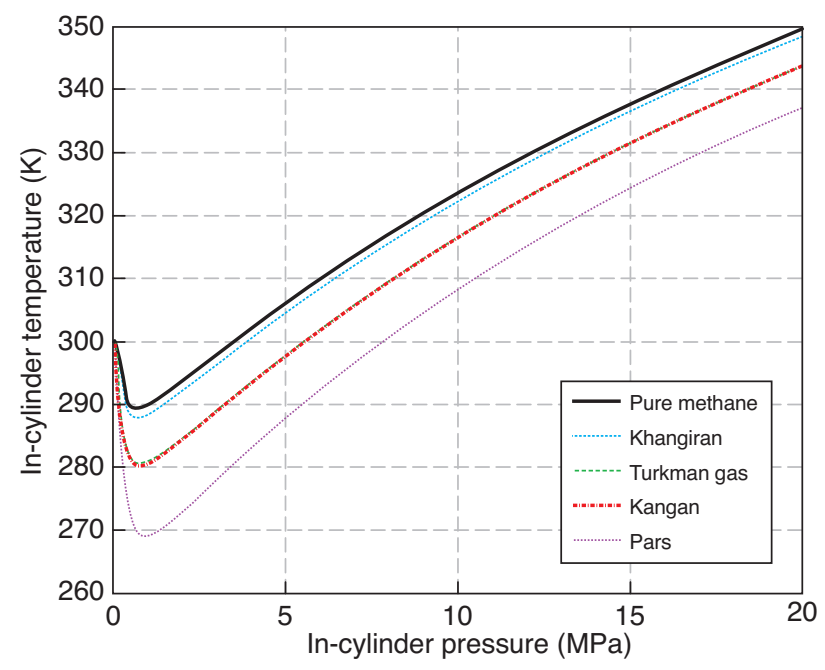

Figure 4

In-cylinder temperature profiles for various natural gas compositions during CNG filling process while initial conditions kept constant at $300 \mathrm{~K}$ and $0.101325 \mathrm{MPa}$. dip in temperature profile, in the early part of the filling is result of the $\mu_{J}$ cooling effect, which the gas undergoes in the isenthalpic expansion through the orifice, from the $20.5 \mathrm{MPa}$ supply pressure to the initially low 1 bar cylinder pressure. This cold gas mixes with and compresses the gas originally in the tank, with the result that the combined mixed gas temperature initially reduces. The lowest in-cylinder temperature occurs when the highest coefficient encountered (see Fig. 3). When the compression and conversion of supply enthalpy energy to cylinder internal energy overcomes the $\mu_{J}$ cooling effect, which becomes smaller as the cylinder pressure increases (see Fig. 3), the mixed gas temperature in the cylinder begins to increase. In this case, the cylinder gas temperature is seen to rise. By comparing the temperature profiles, it could be realized that the lowest temperature throughout of filling corresponds to the gas with lowest methane percentage in the compositions (the gas with highest $\mu_{J}$ coefficient). There is about $14 \mathrm{~K}$ temperature difference in the final incylinder temperature for the gas with the highest methane percentage (Khangiran gas with $98 \%$ methane) and the gas with lowest methane percentage (Pars gas with $87 \%$ methane). The figure clearly shows the significant effect of the natural gas compositions on the temperature profiles.

Figure 5 shows the mass flow rate profiles during filling for various natural gas compositions while initial (ambient) temperature and pressure kept constant at $300 \mathrm{~K}$ and 0.101325 MPa. According to Figure 5, in early part of filling, mass flow rates are constant due to choking. Note from figure 5 that the mass flow rate is highest for the gas with the lowest methane percentage in the composition. This is mainly due to the higher density for such gas. The figure shows the significant effect of the natural gas compositions on the mass flow rate profiles.

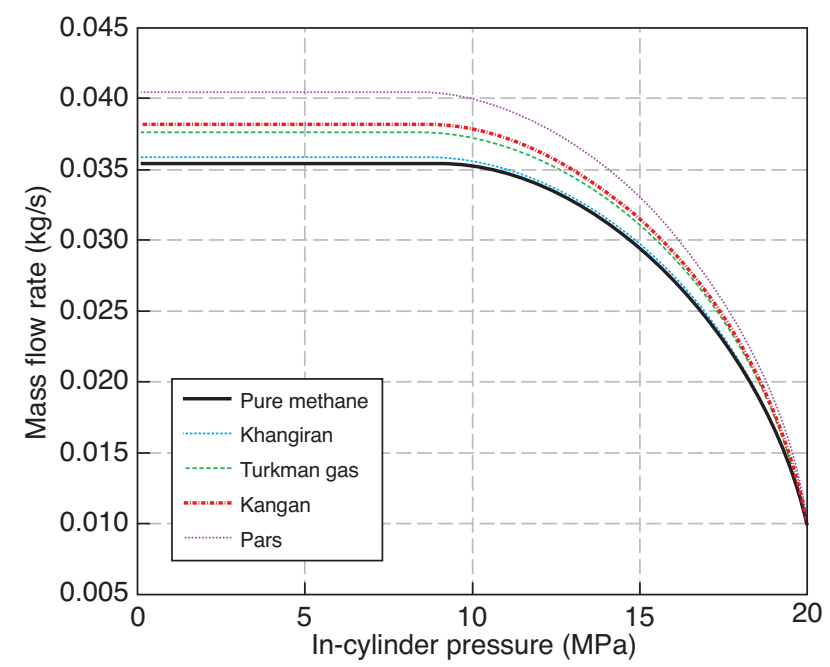

Figure 5

Mass flow rate profiles for various natural gas compositions during the CNG filling process while initial conditions kept constant at $300 \mathrm{~K}$ and $0.101325 \mathrm{MPa}$. 


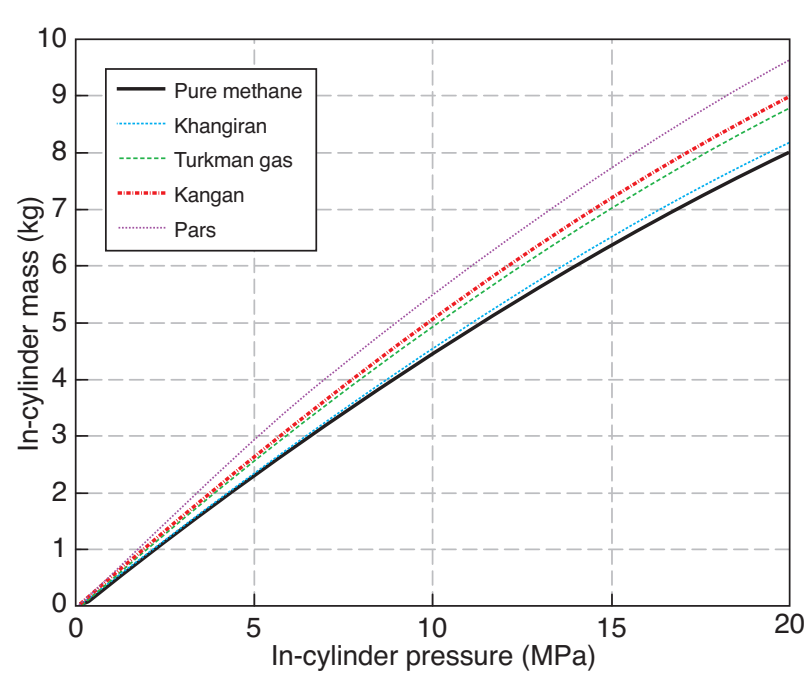

Figure 6

NGV onboard in-cylinder mass variations during filling process for various natural gas compositions while initial conditions kept constant at $300 \mathrm{~K}$ and $0.101325 \mathrm{MPa}$.

In Figure 6, the in-cylinder mass variation is shown. It is expected that the in-cylinder mass would be higher for the gas with higher density. The density is higher for the gas with the lower temperature and the methane percentage. The in-cylinder temperature is also lower for the gas with a low methane percentage (see Fig. 4). Note from the figure 6 that the final in-cylinder mass (charged mass) is higher for the natural gas with the lowest methane percentage. The charged mass for the gas with the lowest methane percentage (Pars gas with $87 \%$ methane) is about $1.5 \mathrm{~kg}$ more than the gas with the highest percentage (Khangiran gas with 98\% methane). This again shows the significant effect of the natural gas compositions on the filling process.

Figure 7 shows the effect of natural gas compositions on time profiles. Note form figure 7 that there is a very small difference between the time profiles. The small effects of the composition on the profiles are due to two opposite effects. The inlet mass flow rate for the gas with lower methane percentage is higher so the time should be lower. In other hand, the in-cylinder mass is higher for such gas, so more time is required for filling.

Previous studies [13-16] show that the initial in-cylinder and reservoir tank temperatures (which could be represented by ambient temperature) have big effects on the final NGV onboard in-cylinder properties. Figure 8 shows the effects of ambient temperature on final NGV onboard in-cylinder temperature for various natural gases. As it is evident from Figure 8, the final in-cylinder temperature is higher for natural gas with the more methane percentage. The significant point is that by increasing the initial (ambient) temperature, the final in-cylinder temperatures increases linearly.

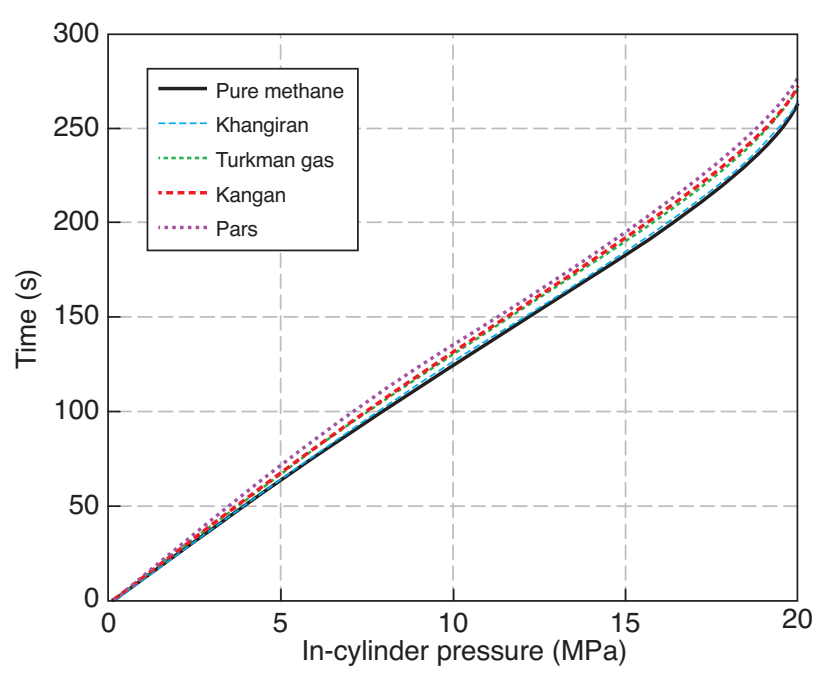

Figure 7

Time profiles for various natural gases during the CNG filling process while initial conditions kept constant at $300 \mathrm{~K}$ and $0.101325 \mathrm{MPa}$.

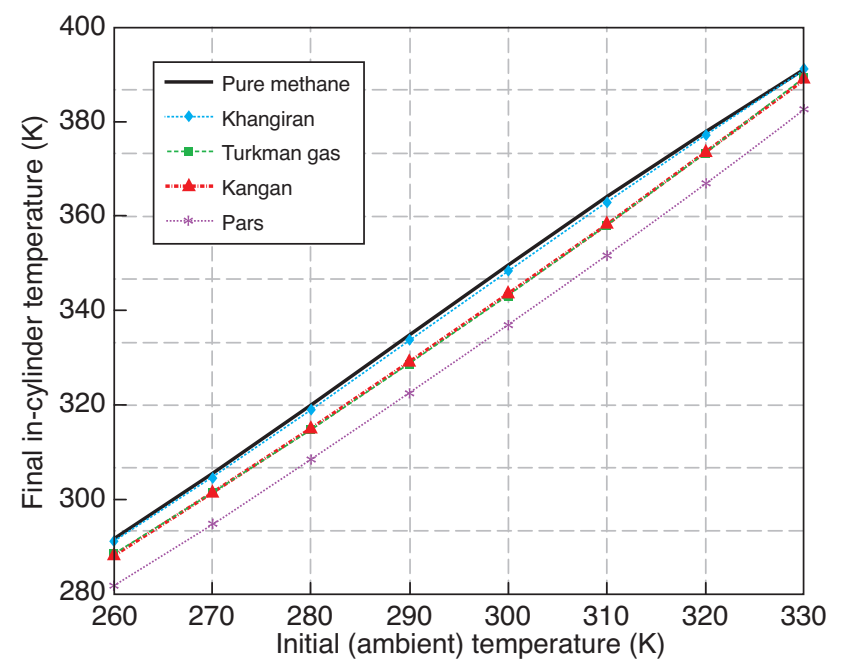

Figure 8

Effect of initial (ambient) temperature on final in-cylinder temperature for various natural gases.

Figure 9 shows the effect of the initial temperature on the charged mass of an empty NGV onboard cylinder for various natural gases. As discussed previously, the charged mass has the direct impact on driving range of a NGV and one of most important problem associated with NGV industry. As indicated in figure 9 the charged mass decreases sharply as ambient temperature increases. The charged mass difference among the studied gases decreases as ambient temperature increases. There is a sharp increase in charged mass as temperature decreases so one could conclude that filling process should be carried out during colder time (nights rather than days). 


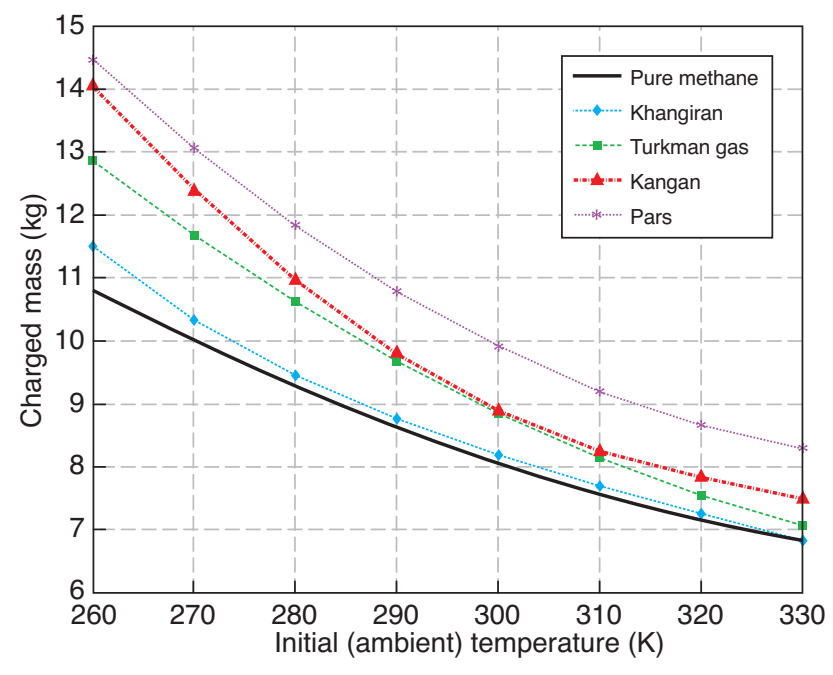

Figure 9

Effect of initial (ambient) temperature on charged mass for various Iranian natural gases.

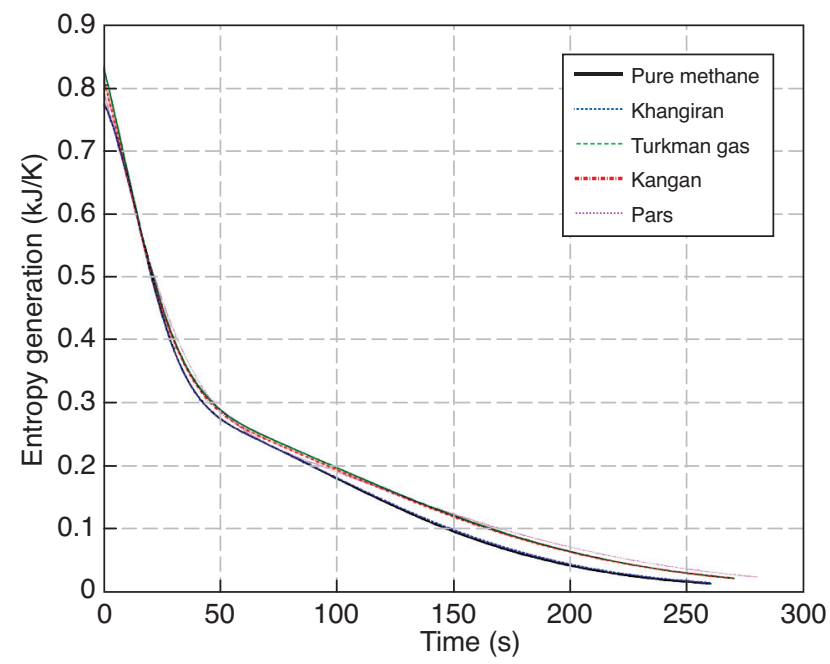

Figure 10

Entropy generation variations during filling for various Iranian natural gases.

As mentioned previously, entropy generation is associated with thermodynamic irreversibilities. Irreversibilities destroy the available work in the filling station. As, the available work is provided by the compressor, one could conclude that as entropy generation is decreased, available work destruction is decreased too. Figure 10 shows the entropy generation variation for the studied natural gases during filling an empty cylinder. As it can be seen, the entropy generation is highest during the early part of filling when the reservoir and cylinder differential pressure is highest. It approaches zero as the value of the differential pressure vanishes.

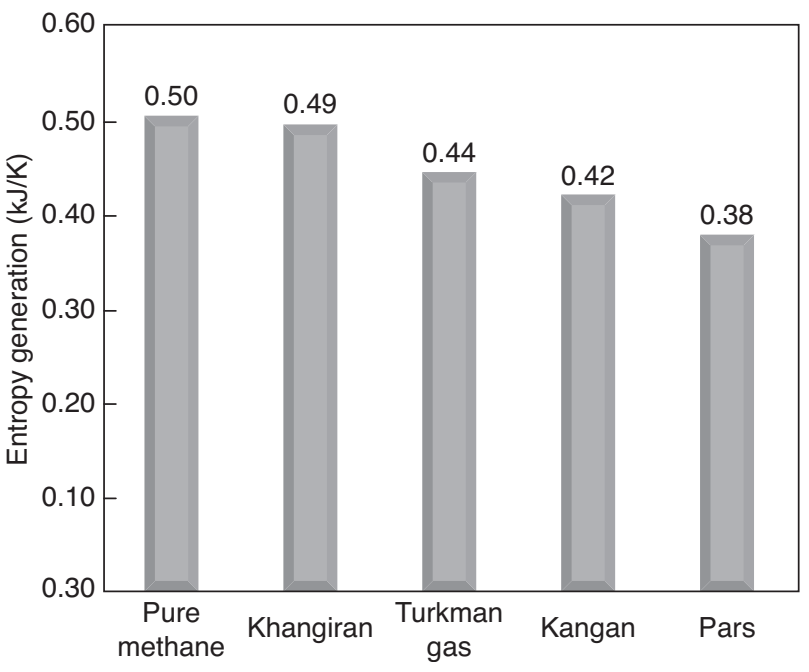

Figure 11

Entropy generation for various Iranian natural gases.

Figure 11 shows the entropy generation for the whole process of filling of an empty cylinder. The entropy generation for natural gas with highest methane percentage (Khangiran gas) is about $0.11 \mathrm{~kJ} / \mathrm{kg} . \mathrm{K}$ more than the gas with lowest methane percentage (Pars gas). This means that the required work by the compressor increases as methane percentage in natural gas composition increases.

\section{CONCLUSION}

The laws of thermodynamics and mass balance have been used as theoretical tools to study the effects of natural gas compositions on the filling process and the final in-cylinder conditions of an onboard NGV cylinder. Based on AGA8 EOS and thermodynamics relationships, the required properties of natural gas mixtures have been computed. As entropy generation is associated with the compressor input work, it is assumed that, as entropy generation reduces, compressor input decreases too.

It is found that the time (filling time) required for bringing up the NGV onboard cylinder to its final pressure (20 MPa) for Pars natural gas type (with about $87 \%$ methane) is about 15 seconds less than Khangiran natural gas (with about $98 \%$ methane). As filling time is between 260 to 275 seconds for studied gases, one could conclude that the composition has small effect on the filling time.

The charged mass for the Pars gas (lowest methane percentage in the composition with $87 \%$ methane) and the Khangiran gas (highest methane percentage in the composition with $98 \%$ methane) are 8 and $9.6 \mathrm{~kg}$ respectively. This shows the significantly of natural gas compositions on the charged mass (20\% here). It should be pointed out that the charged mass is directly related to driving range of a NGV. 
The results also reveal that the entropy generation during filling the gas with lowest methane percentage is about $24 \%$ less than the gas with highest methane percentage.

Considering the above comments, one could conclude that the natural gas composition has big effects on the filling process and the final in-cylinder conditions and should be considered as an important parameter for investigating the filling process.

\section{REFERENCES}

1 Chauveron S. De (1996) Natural Gas for Vehicles, Oil Gas Sci. Technol. 51, 5, 729-741.

2 Tilagone R., Venturi S., Monnier G. (2006) Natural Gas - an Environmentally Friendly Fuel for Urban Vehicles: the Smart Demonstrator Approach, Oil Gas Sci. Technol. 61, 1, 155-164.

3 ISO 11439 (2000) Gas Cylinders - High Pressure Cylinders for the Onboard Storage of Natural Gas as a Fuel for Automotive Vehicles.

4 Kountz K. (1994) Modelling the Fast Fill Process in Natural Gas Vehicle Storage Cylinders, American Chemical Society Paper at 207th National ACS Meeting, San Diego, CA (United States), 13-18 Mar 1994.

5 Kountz K., Kenneth J., Blazek C., Christopher F. (1997) NGV Fuelling Station and Dispenser Control Systems, report GRI97/0398, Gas Research Institute, Chicago, Illinois, November.

6 Kountz K., Liss W., Blazek C. (1998) Method and Apparatus For Dispensing Compressed Natural Gas, U.S. Patent 5,752,552, May 19.

7 Kountz K., Liss W., Blazek C. (1998) Automated Process and System For Dispensing Compressed Natural Gas, U.S. Patent $5,810,058$, Sept. 22.

8 Kountz K., Liss W., Blazek C. (1998) A New Natural Gas Dispenser Control System, Paper at 1998 International Gas Research Conference, San Diego, November 3.

9 Liss W.E., Richards M. (2002) Development of a Natural Gas to Hydrogen Fuelling Station, Topical Report for U.S. DOE, GTI02/0193, Sept.

10 Liss W.E., Richards M.E., Kountz K., Kriha K. (2003) Modelling and Testing of Fast-Fill Control Algorithms for Hydrogen Fuelling, National Hydrogen Association Meeting, Washington DC, March.

11 Newhouse N.L., Liss W.E. (1999) Fast Filling of NGV Fuel Containers, SAE Technical Paper 1999-01-3739.

12 Thomas G., Goulding J., Munteam C. (2002) Measurement, Approval and Verification of CNG Dispensers, NWML KT11 Report.

13 Shipley E. (2002) Study of Natural Gas Vehicles (NGV) During the Fast Fills Process, Thesis for Master of Science, College of Engineering and Mineral Resources at West Virginia University.

14 Farzaneh-Gord M., Eftekhari H., Hashemi S., Magrebi M., Dorafshan M. (2007) The Effect of Initial Conditions on Filling Process of CNG Cylinders, The Second International Conference on Modelling, Simulation and Applied Optimization, Abu Dhabi, UAE, March 24-27.
15 Farzaneh-Gord M. (2008) Compressed Natural Gas Single Reservoir Filling Process, Gas Int. Eng. Manage. 48, 6, 16-18.

16 Farzaneh-Gord M., Hashemi S.H., Farzaneh-Kord A. (2008) Thermodynamics Analysis of Cascade Reservoirs Filling Process of Natural Gas Vehicle Cylinders, World Appl. Sci.J.5, 2, 143-149.

17 Farzaneh-Gord M., Deymi-Dashtebayaz M., Rahbari H.R. (2011) Studying Effects of Storage Types on Performance of CNG Filling Stations, J. Nat. Gas Sci. Eng. 3, 334-340.

18 Kim K., Kim H., Kim B., Lee K., Lee K. (2009) Effect of Natural Gas Composition on the Performance of a CNG Engine, Oil Gas Sci. Technol. 64, 2, 199-206.

19 AGA8-DC92 EoS (1992) Compressibility and Super Compressibility for Natural Gas and other Hydrocarbon Gases, Transmission Measurement Committee Report No. 8, AGA Catalog No. XQ 1285, Arlington, VA.

20 ISO-12213-2 (1997) Natural Gas Calculation of Compression Factor-Part 2: Calculation Using Molar-Composition Analysis, ISO, Ref. No. ISO- 12213-2:1997(E).

21 Maríc I., Galovi'c A., S̆muc T. (2005) Calculation of Natural Gas Isentropic Exponent, Flow Meas. Instrum. 16, 1, 13-20.

22 Maríc I. (2005) The Joule-Thomson Effect in Natural Gas FlowRate Measurements, Flow Meas. Instrum. 16, 2, 387-95.

23 Maríc I. (2007) A Procedure for the Calculation of the Natural Gas Molar Heat Capacity, the Isentropic Exponent, and the Joule-Thomson Coefficient, Flow Meas. Instrum. 18, 1, 18-26.

24 Farzaneh-Gord M., Khamforoush A., Hashemi Sh., Pourkhadem Namin H. (2010) Computing Thermal Properties of Natural Gas by Utilizing AGA8 Equation of State, Int. J. Chem. Eng. Appl.1, 1, 20-24.

25 Bejan A. (1979) A Study of Entropy Generation in Fundamental Convective Heat Transfer, J. Heat Transfer 101, 3, 718-725.

26 Bejan A. (1982) Second-Law Analysis in Heat Transfer and Thermal Design, Adv. Heat Transfer 15, 1, 1-58.

27 Bejan A. (1996) Entropy Generation Minimization, CRC, Boca Raton, NY.

28 National Iran Gas Company website available at: www.NIGC.ir.

29 Farzaneh-Gord M., Rahbari H.R. (2012) Numerical Procedures for Natural Gas Accurate Thermodynamics Properties Calculation, J. Engineer. Thermophys., 21, 3, October.

30 Farzaneh-Gord M., Rahbari H.R. (2011) Developing Novel Correlations for Calculating Natural Gas Thermodynamic Properties, Chem. Process Engineer. J. 32, 4, 435-452.

31 Moran M.J., Shapiro H.N. (2007) Fundamentals of Engineering Thermodynamics, 6th Ed., Wiley, ISBN: 0471787353.

32 DIPPR ${ }^{\circledR} 801$ (2004) Evaluated standard thermophysical property values, Design Institute for Physical Properties, Sponsored by AIChE.

Final manuscript received in November 2011 Published online in February 2013

Copyright (C) 2013 IFP Energies nouvelles

Permission to make digital or hard copies of part or all of this work for personal or classroom use is granted without fee provided that copies are not made or distributed for profit or commercial advantage and that copies bear this notice and the full citation on the first page. Copyrights for components of this work owned by others than IFP Energies nouvelles must be honored. Abstracting with credit is permitted. To copy otherwise, to republish, to post on servers, or to redistribute to lists, requires prior specific permission and/or a fee: Request permission from Information Mission, IFP Energies nouvelles, fax.+33147527096, or revueogst@ifpen.fr. 